\title{
Spontaneous Quick Resolution of Uncombable Hair Syndrome-Like Disease
}

\author{
Yuval Ramot Abraham Zlotogorski Vered Molho-Pessach \\ Department of Dermatology, Hadassah Medical Center, The Faculty of Medicine, Hebrew University of Jerusalem, \\ Jerusalem, Israel
}

\section{Established Facts}

- Uncombable hair syndrome (UHS) is a unique type of structural hair disorder.

- Typically, the condition follows a gradual course of recovery around puberty.

\section{Novel Insights}

- We report on a case of UHS that appeared at childhood and resolved abruptly after 9 months.

- Genetic analysis revealed a heterozygous variation in PLCD1, but the relevance to this condition remains unclear.

\section{Keywords}

Uncombable hair syndrome · Hair · Pili trianguli et canaliculi

\begin{abstract}
Uncombable hair syndrome (UHS) is a unique hair shaft disease characterized by frizzy, straw-colored hair, which is resistant to combing and brushing. Familial cases have been described, and recently mutations in genes related to trichohyalin production have been reported as the cause for this condition. UHS usually manifests during early childhood, and gradually resolves at puberty. Herein, we report on a 2-year-old boy whose hair changed to a UHS-like phenotype "overnight" with no apparent trigger. The condition resolved abruptly after 9 months. Genetic analysis revealed a hetero-
\end{abstract}

\section{KARGER}

(c) 2018 S. Karger AG, Basel

E-Mail karger@karger.com

www.karger.com/sad zygous variant in the PLCD1 gene, which has been connected to hair development. This case raises the possibility that a genetic cause can lead to a temporary change in hair shaft appearance, possibly after exposure to a yet unknown external trigger.

(c) 2018 S. Karger AG, Basel

\section{Introduction}

Uncombable hair syndrome (UHS) is a structural hair disorder characterized by unruly hair, usually straw-colored or silvery blond. The hair has a frizzy appearance and protrudes from the scalp in several directions, and is resistant to brushing and combing $[1,2]$. Most of the cas- 
Fig. 1. Abrupt appearance and quick reso-

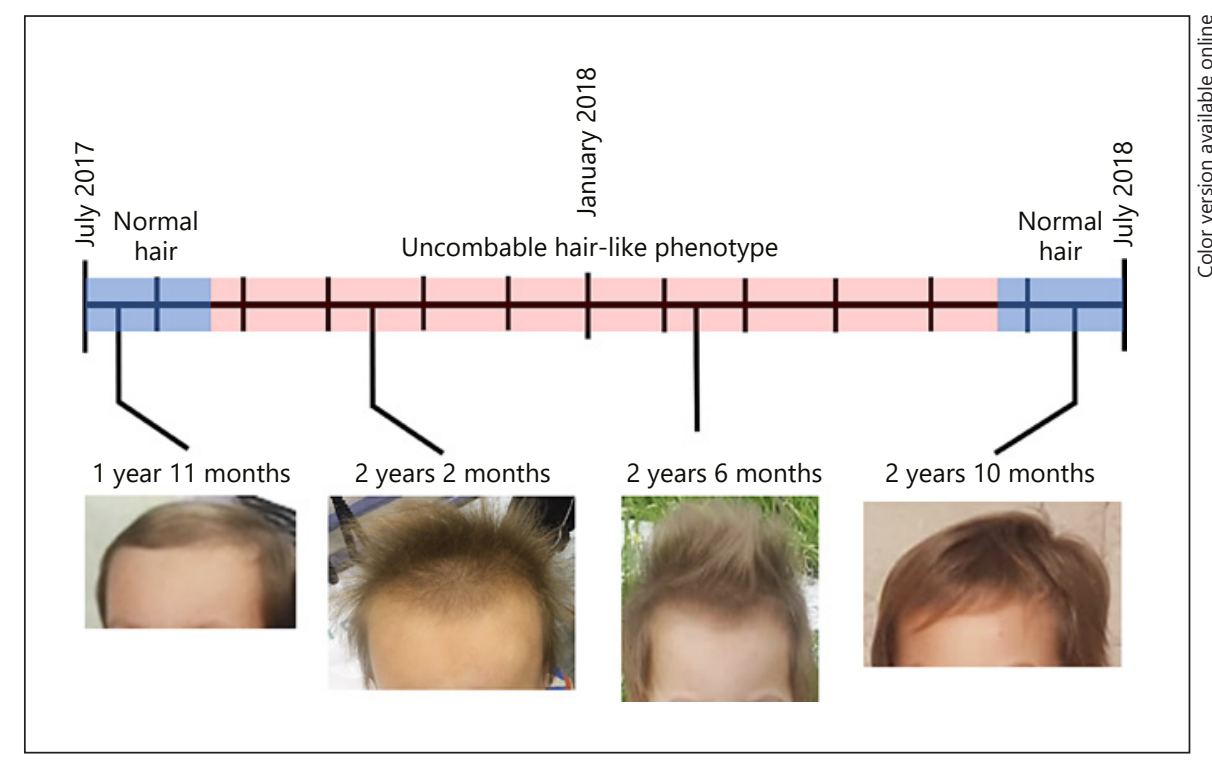

es are sporadic, but familial cases in autosomal recessive or dominant-inheritance patterns have been reported. Recently, mutations in 3 genes involved in the production of the structural hair protein trichohyalin have been reported as the cause for some familial cases of UHS [1].

The UHS phenotype usually first appears during childhood, between the age of 3 months and 12 years [3]. There is currently no effective treatment for the condition. Parents are usually advised to avoid excessive hair manipulation and to provide biotin supplementation, until the hair condition improves gradually during puberty $[1,2]$. Herein, we report the abrupt and spontaneous resolution of an uncombable hair-like phenotype in a young boy.

\section{Case Report}

We evaluated a healthy 2-year-old boy who had an abrupt change in his hair phenotype, changing from soft and easily amenable to combing to frizzy and impossible to brush. According to the parents, this change occurred "overnight." The parents denied any change in hair styling or hair cosmetics. The parents were nonconsanguineous from an Ashkenazi Jew origin, with no history of hair disease. On examination, the hair was brown to straw in color, and appeared to "stand in the air" (Fig. 1). Attempts to comb the hair and flatten it were futile. There was no abnormality of the eyelashes or eyebrows, no cutaneous lesions, and the teeth and nails were normal in appearance. Trichoscopic examination was normal, and microscopic evaluation of the hair shaft did not reveal any abnormality.

Genetic analysis by exome sequencing of DNA extracted from peripheral blood of the affected child and his parents revealed a heterozygous variant (c.595G $>A$ ) in the PLCD1 gene in the mother and child, which was classified as variant of uncertain signifi- cance. No mutations were identified in any of the 3 genes associated with UHS (PADI3, TCHH, and TGM3). The parents of the affected child decided not to treat this condition and opted for regular follow-up in the dermatologic clinic.

After 9 months, the hair returned to its normal appearance and consistency, with no apparent trigger (Fig. 1). According to the parents, this change also happened "overnight". The patient is being followed at the dermatology clinic, and his hair remains normal.

\section{Discussion}

UHS is a rare hair shaft condition, with a unique and "eye-catching" appearance. The changes in hair appearance usually develop progressively during early childhood, and there is gradual amelioration in the hair condition before and during puberty. Differential diagnosis to this condition can be divided into genetic disorders and external factors. The genetic conditions that can mimic UHS mainly include other hair shaft abnormalities, such as pili torti, woolly hair, pili annulati, trichorrhexis invaginata, moniltherix, and trichorrhexis nodosa [4-6]. External factors that can cause hair changes mimicking UHS include photodamage or radiation damage, excess exposure to sunlight or wind, treatment with hair cosmetics, and friction [7-9].

At first, based on the characteristic clinical appearance of the hair and time of development, we assumed that this is a case of UHS. Therefore, we performed genetic analysis and found a variation in PLCD1. PLCD1 encodes the phosphoinositide-specific phospholipase $\mathrm{C}$ delta 1 sub- 
unit, which participates in phosphoinositide metabolism [10]. In humans, variations in PLCD1 have been connected to hereditary leukonychia [11]; however, no changes in the nail phenotype were clinically observed in the mother or the affected child. Phosphoinositide-specific phospholipase C delta 1 is located downstream of Foxn1, which is of critical importance in normal hair development [12], and indeed, mice knocked-out for PLCD1 showed a clear hair phenotype [13]. Nevertheless, the importance of this variation to the hair phenotype observed in the patient described here is unclear. External factors as a cause for the hair condition have been denied several times by the family, in which none of the other members except the affected child showed any hair abnormalities.

In conclusion, we describe a peculiar case of a child with a UHS-like hair phenotype, which lasted for several months and recovered abruptly with no obvious trigger for either the initiation or cessation of this condition. This case raises the question whether there is an underlying genetic cause for a UHS-like condition, which is evident only temporarily and after exposure to a yet unknown trigger. Further follow-up of the patient and his family might provide further clues to this assumption.

\section{Statement of Ethics}

Written consent was obtained from the patient's parents.

\section{Disclosure Statement}

The authors have no conflicts of interest to disclose.

\section{References}

1 Ü Basmanav FB, Cau L, Tafazzoli A, Méchin MC, Wolf S, Romano MT, et al. Mutations in three genes encoding proteins involved in hair shaft formation cause uncombable hair syndrome. Am J Hum Genet. 2016 Dec;99(6): 1292-304

2 Piccolo V, Cirocco A, Russo T, Piraccini BM, Ronchi A, Argenziano G. Hair cross sectioning in uncombable hair syndrome: an easy tool for a complex diagnosis. J Am Acad Dermatol. 2018 Jun;79(4):e63-4.

3 Swamy SS, Ravikumar BC, Vinay KN, Yashovardhana DP, Aggarwal A. Uncombable hair syndrome with a woolly hair nevus. Indian J Dermatol Venereol Leprol. 2017 JanFeb;83(1):87-8.

4 Ramot Y, Molho-Pessach V, Meir T, AlperPinus R, Siam I, Tams S, et al. Mutation in KANK2, encoding a sequestering protein for steroid receptor coactivators, causes keratoderma and woolly hair. J Med Genet. 2014 Jun;51(6):388-94.
5 Ramot Y, Zlotogorski A. Molecular genetics of alopecias. Curr Probl Dermatol. 2015;47: 87-96.

6 Ramot Y, Zlotogorski A. The twisting tale of woolly hair: a trait with many causes. J Med Genet. 2015 Apr;52(4):217-23.

7 Jeon SY, Pi LQ, Lee WS. Comparison of hair shaft damage after UVA and UVB irradiation. J Cosmet Sci. 2008 Mar-Apr;59(2):151-6.

8 Mukherjee SS, Chandrashekar BS. Diffuse wooly hair mimicking as uncombable hair syndrome! Indian J Pediatr Dermatol. 2017; 18(2):135-37.

9 Santos Nogueira AC, Joekes I. Hair color changes and protein damage caused by ultraviolet radiation. J Photochem Photobiol B. 2004 May;74(2-3):109-17.
10 Stewart AJ, Mukherjee J, Roberts SJ, Lester D, Farquharson C. Identification of a novel class of mammalian phosphoinositol-specific phospholipase $\mathrm{C}$ enzymes. Int J Mol Med. 2005 Jan;15(1):117-21.

11 Kiuru M, Kurban M, Itoh M, Petukhova L, Shimomura Y, Wajid M, et al. Hereditary leukonychia, or porcelain nails, resulting from mutations in PLCD1. Am J Hum Genet. 2011 Jun;88(6):839-44.

12 Nakamura Y, Ichinohe M, Hirata M, Matsuura H, Fujiwara T, Igarashi T, et al. Phospholipase C-delta 1 is an essential molecule downstream of Foxn1, the gene responsible for the nude mutation, in normal hair development. FASEB J. 2008 Mar;22(3):841-9.

13 Liu YM, Liu W, Jia JS, Chen BZ, Chen HW, Liu Y, et al. Abnormalities of hair structure and skin histology derived from CRISPR/ Cas9-based knockout of phospholipase Cdelta 1 in mice. J Transl Med. 2018 May;16(1): 141 